\title{
Association between Coronary Artery Disease and Erectile Dysfunction in Patients of a University Hospital
}

\author{
Nicole Favretto Baltazar1, Carolina Dario Fischer ${ }^{1}$, Stefanie Basilio \\ Medeiros ${ }^{1}$, Paola Beatriz Souza Ferrés ${ }^{1}$, Luis Cesar Fava \\ Spessoto ${ }^{3}$, Moacir Fernandes de Godoy², Fernando Nestor Facio \\ $\mathrm{Jr}^{3} \mathrm{P}$
}

${ }^{1}$ Undergraduate student School of the Medicine in São Jose Rio Preto - FAMERP

${ }^{2}$ Professor of the Cardiology and Cardiovascular Surgery Department - Hospital de Base - FAMERP

${ }^{3}$ Professor of the Surgical Specialties Department - Hospital de Base - FAMERP

\begin{abstract}
Background: Over the last decade, male sexual dysfunction has become a topic of great interest to clinicians, researchers and to public health managers. Many chronic coronary artery disease patients in Brazil suffer from erectile dysfunction (ED) and most do not feel comfortable about reporting their complaints. One of the main protection mechanisms against the onset and progression of cardiovascular diseases is physical activity. The objective of this study was to investigate the association between coronary artery disease and the degree of ED in a university hospital, as well as its relationship with age and modifiable risk factors such as low levels of physical activity and smoking. Methods: Sixty-seven patients with coronary artery disease were evaluated at a university hospital in a cross-sectional observational study using the International Index of Erectile Function (IIEF) questionnaire. Results: No association was found for the degree of ED with coronary artery disease, physical exercise or smoking. However, the results of this questionnaire showed that $79 \%$ these patients had some degree of ED. Conclusions: In this study, no association was found between patients with coronary artery disease and the degree of ED but, at a cut-off point of 21, the IIEF was very sensitive to indicate the presence of concomitant coronary artery disease.
\end{abstract}

Keywords: Coronary Artery Disease, Erectile Dysfunction, Physical Activity, Smoking

\section{Introduction}

Over the last decade, male sexual dysfunction has become a topic of great interest to clinicians, researchers and to public health managers. This condition involves many aspects that often raise doubts and difficulties for both health professionals and patients ${ }^{1}$.

Erectile dysfunction (ED) is the inability of a man to obtain or maintain penile erection sufficient to perform sexual intercourse satisfactorily ${ }^{2}$. Several physical and psychological components are involved in erectile function, including hormonal, neurological, vascular and cavernous body diseases ${ }^{2,3}$. Studies have demonstrated a high prevalence of ED in men with cardiovascular diseases, since both diseases have several risk factors in common ${ }^{4,5}$.
Penile erection is regulated by the relaxation of the cavernous arteries and the smooth muscle of the corpora cavernosa, which is coordinated by a neuromyo-vascular-endocrine complex mechanism mediated by the sympathetic and parasympathetic nervous systems, and the pituitary-gonadal axis ${ }^{6-8}$. It is believed that the problem of ED is an imbalance between contraction and relaxation of the smooth muscle of the corpora cavernosa ${ }^{9,10}$.

A general medical history is important to identify specific risk factors that may be responsible for or contribute to ED. These factors include age, diabetes mellitus, vascular diseases, coronary artery disease (CAD), pelvic or penile trauma, high total cholesterol levels, low high-density lipoprotein levels (HDL), drug use, neurological diseases, radiotherapy,

This article is published under the terms of the Creative Commons Attribution License 4.0 Author(s) retain the copyright of this article. Publication rights with Alkhaer Publications.

Published at: http://www.ijsciences.com/pub/issue/2017-07/

DOI: 10.18483/ijSci.1371; Online ISSN: 2305-3925; Print ISSN: 2410-4477 
depression, alcohol intake, and inappropriate interpersonal relationships 9-13. Hypertension increases the risk of $\mathrm{ED}$, however, in patients with $\mathrm{CAD}$, it exerts a protective effect, even though $\mathrm{CAD}$ is an important risk factor for atherosclerosis. This is because higher pressures allow a greater blood flow and consequent increase in perfusion, essential for erectile function. In the long term, however, arterial hypertension is an aggravating factor for both ED and CAD $^{14}$.

A sedentary lifestyle may also be considered a risk factor for ED. The rate of ED in sedentary individuals is between 43 and $70 \%$, and thus regular physical activity can reduce the risk of ED by one third. However, some studies did not find any relationship between the practice of physical exercises and ED, possibly due to the negative influence of physiological aging and psychogenic factors, both of which were not considered in the studies ${ }^{15}$.

Smoking causes an adverse effect on erectile function, accentuating the risk due to vascular disease or hypertension ${ }^{16}$. Several epidemiological studies have shown that smoking not only increases the risk of ED, but also increases the severity of ED associated with other cardiovascular risks (hypertension, diabetes mellitus and dyslipidemia) and aging. Clinical and epidemiological studies have demonstrated that ED caused by smoking is associated with penile perfusion deficiency and acute vasospasm of the penile arteries. Moreover, longterm smoking and heavy smoking have deleterious effects on the vascular endothelium and peripheral nerves $^{13}$.

It is important to note that although several studies on the prevalence, etiology, pathophysiology, diagnosis and treatment of ED have been carried out, little is known about the behavior of CAD patients to accept treatment ${ }^{11}$. The objective of this study was to investigate the association between $\mathrm{CAD}$ and the degree of ED in a university hospital, as well as its relationship with age and modifiable risk factors such as low level of physical activity and smoking.

\section{Patients and Methods}

A cross-sectional observational study was performed using primary data collected throughout the research. All over 18-year-old male patients with CAD, submitted to a hemodynamic study were invited to participate in a follow-up program of the cardiology department of a university hospital concerning signs and symptoms of coronary insufficiency. This study was submitted and approved by the Ethics Committee on Human Research of the Medical School in São José do Rio Preto, SP. Patients were informed regarding the nature and objectives of the study. All participants signed a consent form before participating in the research, in agreement and within the laws and regulations regarding clinical research in Brazil.

Patients submitted to prostate or pelvic surgeries, or pelvic radiotherapy and those unable to communicate or who did not agree to participate in the study were excluded from the study.

Data on CAD patients were collected from medical records and through an interview using the selfadministered International Index of Erectile Function (IIEF) questionnaire. According to the IIEF, ED is classified into several degrees of severity depending on the patient's score: above 21 points: normal erectile function; 17-21: mild ED; 12-16: mild to moderate ED; 8-11: moderate ED; and 1-7: severe $\mathrm{ED}^{16}$.

Hemodynamic examinations were performed by experienced physicians and reassessed by a single hemodynamicist for consistency. Patients were also questioned about physical activity, whether they accepted treatment for ED and the degree of nicotine dependence. The Fagerström nicotine dependence test (FNDT) was used, which classifies patients by several degrees of severity: Non-smoker - 0;1-4 very low/low dependence; 5 - average dependence; 610 - high/very high dependence ${ }^{17}$.

Presence of CAD was attributed by means of a review of the patient's records, based on the percentage of obstruction of arteries $(>50 \%)$ : right coronary, anterior descending, circumflex and trunk or the presence of stents.

\section{Statistical analysis}

The Mann-Whitney test was used to compare the IIEF scores between the sedentary and non-sedentary groups, as the data was nonparametric. Sensitivity and specificity calculations were made for the IIEF scores using a cut-off point of 21 for the diagnosis of ED. Fisher's exact test was used to identify any possible correlation between the degree of CAD and acceptance or not of treatment for ED. P-values $<0.05$ were considered significant.

\section{Results}

Sixty-seven patients were evaluated; 14 (21\%) had normal erectile function and $53(79 \%)$ had some degree of ED according to the IIEF questionnaire.

Thirty-nine patients had CAD (58\%) according to the hemodynamic examination. The median age was 61 
years (range: $33-84$ years). The relationship of the

IIEF scores with CAD is presented in Table 1.

Table 1 - Relationship between International Index of Erectile Function (IIEF) scores and coronary artery disease

IIEF With obstructive coronary lesion Without obstructive coronary
lesion

Normal erectile function

6

17

12

2

2

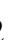

\section{8}

2

4

1-7: severe ED

activity. The median IIEF score among active individuals was 19, while the median score of sedentary subjects was 17 ; both scores of 17 and 19 are classified as mild ED. A p-value $=0.9846$ was calculated using the Mann-Whitney test, so there was no statistically significant difference between the groups (Figure 1).

As for physical activity, only $34.3 \%$ of the patients identified themselves as active, with $65.7 \%$ stating that they did not practice any type of regular physical

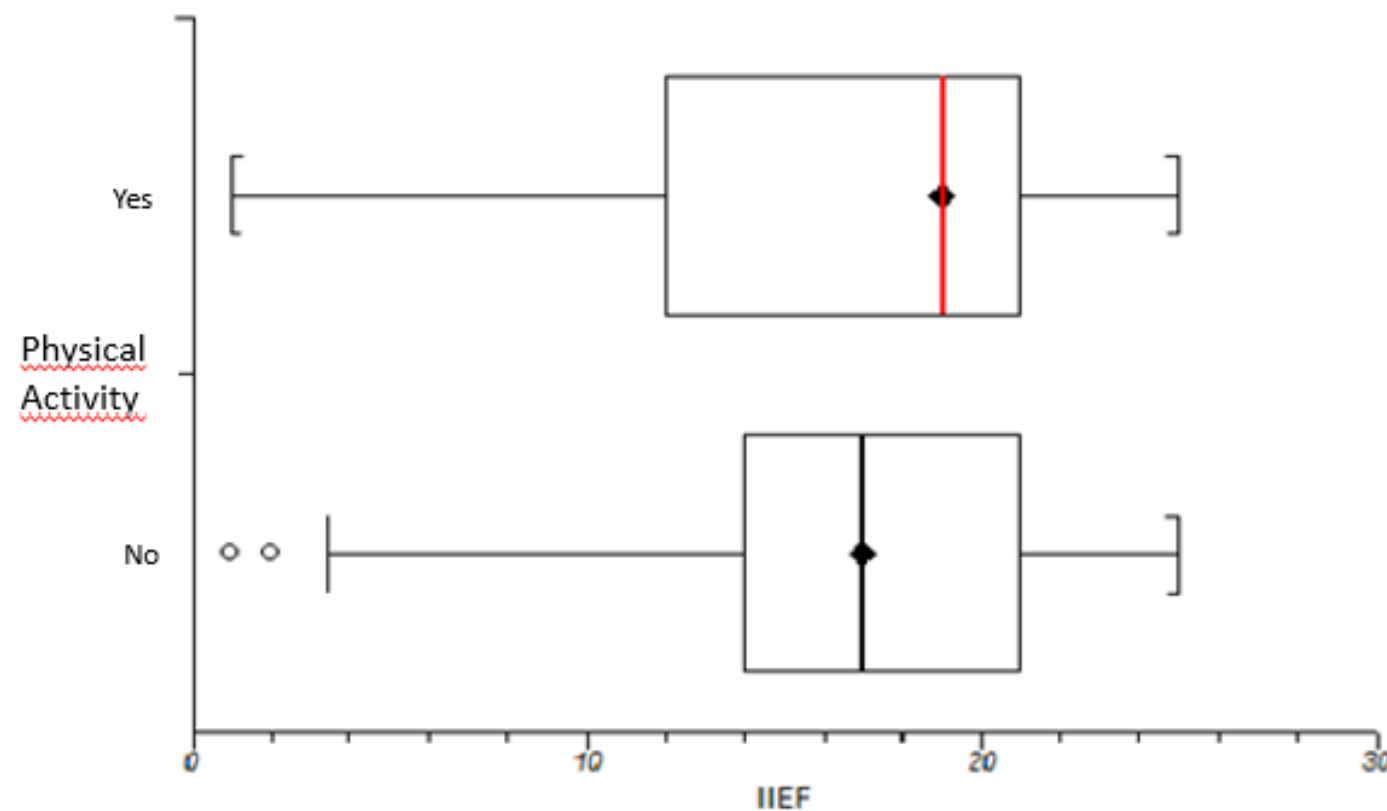

Figure 1 - Box plot of the values obtained with the IIEF questionnaires according to physical activity.

Regarding smoking, $38.8 \%$ of the patients said they were smokers and $61.2 \%$ reported never having smoked. Among the smokers, 26.9\% (10.44\% of the patients) had very low or low degrees of dependency according to the FNDT, while $73.9 \%$ (28.35\% of the patients) had high or very high degrees of dependency and none had a medium degree of dependency (Figure 2). 


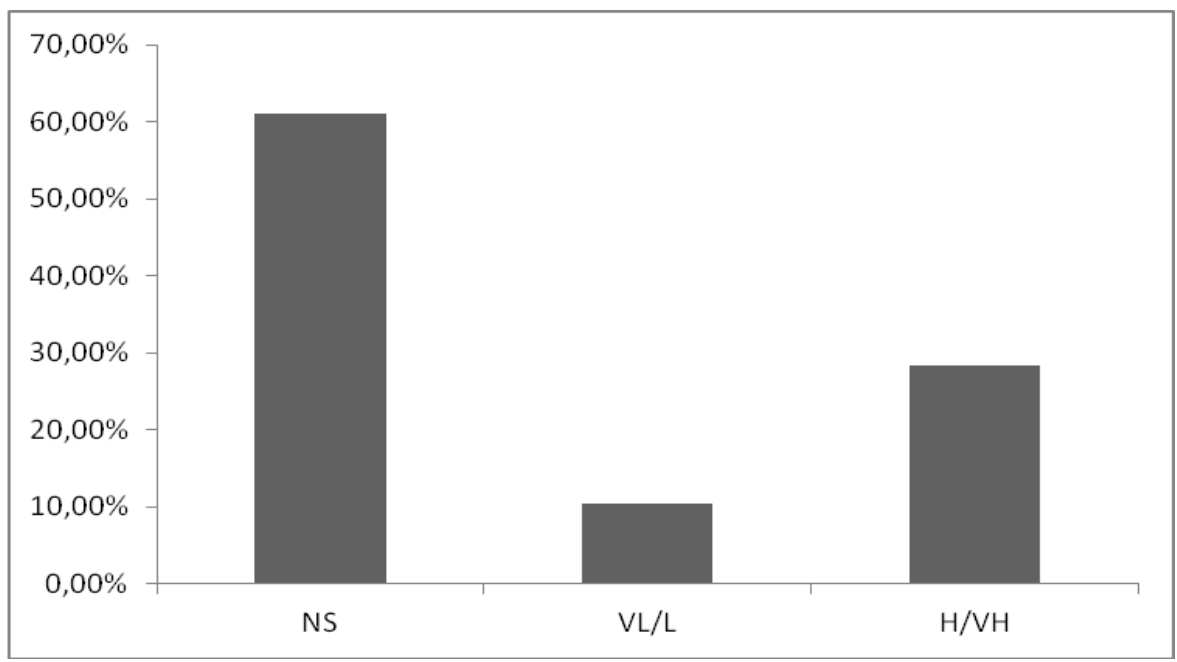

Figure 2 - Degree of dependency on smoking (NS = non smokers; VL/L = very low/low level; VH/H = very high/high level)

\section{Discussion}

Although several studies have shown a high prevalence of ED in men with cardiovascular diseases, we have had some difficulties investigating this condition due to the patients' reluctance to collaborate with studies on sexuality. This high prevalence occurs because both diseases have several common risk factors ${ }^{4,5}$.

The most common organic causes of ED are vascular abnormalities, often associated with atherosclerosis and diabetes mellitus ${ }^{18-21}$. In the United States, atherosclerosis is a risk factor for ED in $70 \%$ of over 60 -year-old men ${ }^{22}$. Several studies have shown that ED is a marker for cardiovascular diseases, and ED symptoms may appear two to three years before the symptoms of subclinical heart disease. ED has been associated with the severity of ischemic heart disease as the more severe the ED the greater the degree of coronary disease ${ }^{23}$.

Many chronic CAD patients in Brazil suffer from ED and most do not feel comfortable about reporting their complaints. It is important to remember that one of the main protection mechanisms against the onset and progression of cardiovascular diseases is physical activity.

The prevalence of ED in this study was $79 \%$; higher than described in some other studies ${ }^{24,25}$. In studies investigating $\mathrm{CAD}$ and $\mathrm{ED}$, the prevalence was reported at $84 \%{ }^{26,27}$.

The current study demonstrated that IIEF has a sensitivity of $84 \%$ to identify CAD when the IIEF scores are $\leq 21$ (the cutoff point for ED). Thus, the IIEF is a very sensitive noninvasive test to indicate the need for further investigation, since ED appears as an early symptom of cardiovascular disease ${ }^{19,20}$. This result corroborates evidence of an association between ED and heart disease ${ }^{28}$.

According to the Framingham risk score, research shows that the relative risk of 30- to 39-year-old men developing $\mathrm{CAD}$ within 10 years of the diagnosis of moderate to severe ED is $1.1 \%$; this risk rises to $4.9 \%$ in the 60- to 69-year age group ${ }^{26}$. Based on this, the diagnosis of ED may be very important to accompany and treat coronary diseases early.

In addition, stress tests with physical activity can only identify major lesions (50-70\% of stenosis), whereas ED is sensitive for stenosis $<50 \%$. ${ }^{23}$ Thus, the use of the IIEF questionnaire in the daily practice of hemodynamics units would be extremely useful.

This study had some limitations such as a small number of patients analyzed and some of the patients interviewed were illiterate and asked for help reading the IIEF questionnaire, which may have made them omit the true answer.

The prevalence of ED in cardiac patients in the current study was $84 \%$, which demonstrates the high rate of ED in men with cardiovascular diseases. Since the symptoms of ED appear a few years before the symptoms of coronary disease, a tool that would assist in the diagnosis of this dysfunction may have important implications.

Although the sample size in this study was small, we stress the clinical relevance of the research, since the increase in the use of non-invasive methods, such as the IIEF, may help the early monitoring and diagnosis of heart diseases. 


\section{Conclusions}

In this study, there was no association between patients with CAD and the degree of ED, however, at the cut-off point of 21, the IIEF was very sensitive to indicate the presence of concomitant CAD. The study did not show an association between low levels of physical activity and the severity of ED. Forty percent of the patients submitted to a hemodynamic study in a university hospital are smokers, and of these approximately $74 \%$ have a high or very high degree of nicotine dependence.

\section{Conflicts of interest: none}

\section{References}

1) Montorsi P, Ravagnani PM, Vlachopoulos C. Clinical significance of erectile dysfunction developing after acute coronary event: exception to the rule or confirmation of the artery size hypothesis? Asian J Androl 2015;17(1):21-5.

2) Melman A. Evaluation and management of erectile dysfunction. Surg Clin North Am 1988;68(5):965-81

3) Mulcahy JJ. Current approach to the treatment of penile implant infections. Ther Adv Urol 2010;2(2):69-75.

4) Dzenkeviciute V, Petrulioniene Z, Sapoka V, Kasiulevicius V. Association between erectile dysfunction and asymptomatic cardiovascular damage in middle-aged men. Medicina (Kaunas) 2013;49(12):510-6.

5) Gandaglia G, Salonia A, Passoni N, Montorsi P, Briganti A, Montorsi F. Erectile dysfunction as a cardiovascular risk factor in patients with diabetes. Endocrine 2013;43(2):285-92.

6) Kapur V, Schwarz ER. The relationship between erectile dysfunction and cardiovascular disease. Part I: pathophysiology and mechanisms. Rev Cardiovasc Med 2007;8(4):214-9.

7) Sivalingam S, Hashim H, Schwaibold H. An overview of the diagnosis and treatment of erectile dysfunction. Drugs 2006;66(18):2339-55.

8) El-Sakka AI, Morsy AM, Fagih BI. Severity of erectile dysfunction could predict left ventricular diastolic dysfunction in patients without overt cardiac complaint. J Sex Med 2011;8(9):2590-7.

9) Francavilla S, Bocchio M, Pelliccione F, Necozione S, Francavilla F. Vascular aetiology of erectile dysfunction. Int J Androl 2005;28 Suppl 2:35-9.

10) El-Sakka AI, Morsy AM, Fagih BI, Nassar AH. Coronary artery risk factors in patients with erectile dysfunction. J Urol 2004;172(1):251-4.

11) Gazzaruso C, Giordanetti S, De Amici E, Bertone G, Falcone C, Geroldi D, et al. Relationship between erectile dysfunction and silent myocardial ischemia in apparently uncomplicated type 2 diabetic patients. Circulation 2004;110(1):22-6.

12) Brunner H, Cockcroft JR, Deanfield J, Donald A, Ferrannini E, Halcox J, et al. Endothelial function and dysfunction. Part II: Association with cardiovascular risk factors and diseases. A statement by the Working Group on Endothelins and Endothelial Factors of the European Society of Hypertension. J Hypertens 2005;23(2):233-46.

13) Fernandes-Maia ACS, Pinheiro FP, Arruda JGF, Spessoto LCF, Arrruda PFF, Fácio Jr FN. Cardiovascular risk factors in patients with erectile dysfunction. Int J Sci 2016;5(2):32-37.

14) Spessoto LC, Facio FN Jr, de Arruda JG, Arruda PF, Gatti M, Antoniassi TS, et al. Association of hypertension with erectile function in chronic peripheral arterial insufficiency patients. J Clin Med Res 2016;8(8):582-4.

15) Pinheiro FP, Fernandes-Maia ACS, Arruda JGF, Spessoto LCF, Arrruda PFF, Fácio Jr FN. Relationship between sedentary lifestyle and erectile dysfunction. Int J Sci 2015;4(12):68-72.

16) Rosen RC, Cappelleri JC, Smith MD, Lipsky J, Pena BM. Development and evaluation of an abridged, 5item version of the International Index of Erecile Functile Function (IIEF-5) as a diagnostic tool for erecile dysfunction. Int J Impot Res 1999;11(6):319-26.

17) Nunes SOV, Vargas HO, Nunes LVA, Noto MVN. A dependência do tabaco. In Nunes SOV and Castro MRP., orgs. Tabagismo: abordagem, prevenção e tratamento [online]. Londrina: EDUEL, 2011. pp. 41 54.

18) 18. Mulhall J, Teloken P, Brock G, Kim E. Obesity, dyslipidemias and erectile dysfunction: a report of a subcommittee of the sexual medicine society of North America. J Sex Med 2006;3(5):778-86.

19) Montorsi P, Ravagnani PM, Galli S, Rotatori F, Veglia F, Briganti A, et al. Association between erectile dysfunction and coronary artery disease. Role of coronary clinical presentation and extent of coronary vessels involvement: the COBRA trial. Eur Heart J 2006;27(22):2632-9.

20) Sekoranja L, Bianchi-Demicheli F, Gaspoz JM, Mach F. [Erectile dysfunction: a potential useful marker for cardiovascular disease]. Rev Med Suisse 2006;2(58):774-6, 78.

21) Gupta BP, Murad MH, Clifton MM, Prokop L, Nehra A, Kopecky SL. The effect of lifestyle modification and cardiovascular risk factor reduction on erectile dysfunction: a systematic review and meta-analysis. Arch Intern Med 2011;171(20):1797-803.

22) Canat L, Cicek G, Atis G, Gurbuz C, Caskurlu T. Is there a relationship between severity of coronary artery disease and severity of erectile dysfunction? Int Braz J Urol 2013;39(4):465-73.

23) Hackett G., Krychman M., Baldwin D, Bennett N, ElZawahry A, Graziottin A, et al. Coronary heart disease, diabetes, and sexuality in men. J Sex Med 2016;13(6): 887-904

24) Moreira $\mathrm{ED} \mathrm{Jr}$, Abdo $\mathrm{CH}$, Torres $\mathrm{EB}$, Lobo $\mathrm{CF}$, Fittipaldi JA. Prevalence and correlates of erectile dysfunction: results of the Brazilian study of sexual behavior. Urology 2001;58(4):583-8

25) Moreira ED Jr, Bestane WJ, Batolo EB, Fittipaldi JA. Prevalence and determinants of erectile dysfunction in Santos, Southeastem Brazil. São Paulo Med J 2002;120(2):49-54

26) Sai Ravi Shanker A, Phanikrishna B, Bhaktha Vatsala Reddy C. Association between erectile dysfunction and coronary artery disease and its severity. Indian Heart J 2013;65(2):180-6.

27) Salem S, Abdi S, Mehrsai A, Saboury B, Saraji A, Shokohideh V, et al. Erectile dysfunction severity as a risk predictor for coronary artery disease. J Sex Med 2009;6(12):3425-32.

28) Ortiz J, Ortiz ST, Monaco CG, Yamashita CH, Moreira MC, Monaco CA. [Erectile dysfunction: a marker for myocardial perfusion impairment?]. Arq Bras Cardiol 2005;85(4):241-6. 